\title{
Antibiotic prophylaxis in open inguinal hernia repair: a literature review and summary of current knowledge
}

\author{
Mateusz T. Zamkowski ${ }^{1}$, Wojciech Makarewicz ${ }^{2,3}$, Jerzy Ropel ${ }^{1}$, Maciej Bobowicz², Michał Kąkol ${ }^{4}$, Maciej Śmietański ${ }^{5,6}$ \\ ${ }^{1}$ Regional Health Centre, Kartuzy, Poland \\ ${ }^{2}$ Department of Oncological Surgery, Medical University of Gdansk, Gdansk, Poland \\ ${ }^{3}$ Koscierzyna Specialist Hospital, Koscierzyna, Poland \\ ${ }^{4}$ Voivodeship Oncology Centre, Gdansk, Poland \\ ${ }^{5}$ Department of General Surgery, Hospital, Puck, Poland \\ ${ }^{6} 2^{\text {nd }}$ Department of Radiology, Medical University of Gdansk, Gdansk, Poland
}

Videosurgery Miniinv 2016; 11 (3): 127-136

DOI: $10.5114 /$ wiitm.2016.62800

\begin{abstract}
More than 1 million inguinal hernia repairs are performed in Europe and the US annually. Although antibiotic prophylaxis is not required in clean, elective procedures, the routine use of implants (90\% of inguinal hernia repairs are performed with mesh) makes the topic controversial. The European Hernia Society does not recommend routine antibiotic prophylaxis for elective inguinal hernia repairs. However, the latest randomized controlled trial, published by Mazaki et al., indicates that the use of prophylaxis is effective for the prevention of surgical site infection. Unnecessary prophylaxis contributes to the development of bacterial resistance and significantly increases healthcare costs. This review documents clinical trials on inguinal hernia repairs with mesh and summarizes the current knowledge. It also tries to solve certain problems, namely: what constitutes a real risk factor, late-onset infection, and how the "surgical environment" impacts on the need to use antibiotic prophylaxis.
\end{abstract}

Key words: hernia, mesh repair, inguinal hernia repair, surgical site infection, antimicrobial prophylaxis, antibiotic prophylaxis.

\section{Introduction}

Inguinal hernia repair procedures belong to the group of the most commonly performed procedures in general surgery and are among the first procedures to be carried out by junior surgeons during their professional training. More than one million operations for hernia are performed in Europe and the United States each year [1-3]. In Poland, approximately 60 thousand inguinal canal repair procedures are carried out each year, $60 \%$ of which are performed using a mesh (according to the National Health Fund [NFZ]). Data also include children, in whom we do not routinely use mesh in inguinal canal repairs. After excluding children, the percentage of mesh procedures rises to 90 , but the general number of mesh procedures drops to 45 thousand.

Over the past 20 years, about 300 research papers, doctoral dissertations and conference communications on inguinal hernia have been written and/ or presented in Poland [4]. Elective inguinal canal repair surgery is considered to be a clean procedure which does not, as such, require antibiotic prophylaxis [1-6]. Over the years, the number of implants used during inguinal hernia repair procedures has considerably increased, and the Lichtenstein method has become the gold standard in the management of this condition [7]. 
Routine use of antibiotic prophylaxis in elective inguinal hernia repair procedures using an implant is still controversial. The rate of surgical site infection (SSI) following hernia repair procedures reported in the international literature ranges between $0 \%$ and $14 \%[5,6,8-12]$.

Most double-blind randomised controlled trials (RCTs) do not confirm that use of antibiotic prophylaxis statistically reduces the rate of SSI [1, 13-20].

On the other hand, according to the surveys conducted at hospitals in London and the South East of England, an overwhelming majority of surgeons are in favour of using antibiotic prophylaxis when performing hernia repair procedures with a mesh (84\%). They base this opinion on their own beliefs and experience. Furthermore, 22 out of 28 hospitals interrogated in this region include antibiotic prophylaxis in their guidelines [21].

The European Hernia Society (EHS) does not recommend routine antibiotic prophylaxis for elective inguinal hernia repair procedures using a mesh in low-risk patients but recommends considering prophylaxis where there are patient-related risks (recurrence, old age, immunosuppression) or procedure-related risks (long duration of surgery, drainage). This applies to centres where the SSI rate for elective clean surgery is below 5\% [22].

The supplement to the EHS guidelines and the comment of the Polish Working Group for Recommendations state that in the setting of Polish hospitals, the use of antibiotic prophylaxis reduces the risk of surgical wound infection in open hernia repair procedures $[4,23]$.

\section{Antibiotic prophylaxis in clean procedures}

Antibiotic prophylaxis is an activity aimed at reducing the intraoperative level of microorganisms to a quantity which can be successfully dealt with by the patient's immune system. This prophylaxis involves the administration of a drug before bacteria adhere to host tissues or host proteins in the surgical field or the reduction of the quantity of colonising bacteria at that site $[24,25]$.

Indications for administering a prophylactic antibiotic result from clinical trials in which a reduced number of infectious complications has been demonstrated. Prophylaxis is also recommended in situations where potential SSI could lead to dramatic consequences [25].

In 1964, the US National Research Council (NRC) proposed a classification of surgical wounds that would predict the risk of SSI. The current classification, modified by the Centers for Disease Control and Prevention (CDC), distinguishes four classes of wounds: clean, clean-contaminated, contaminated, and dirty (see Table I) [25, 26]. This classification aims to assess the risk of bacterial infection and potential complications in the form of SSI in perioperative management [26].

Table I. Types of surgical wounds and the risk of infection

\begin{tabular}{|llc|}
\hline \multicolumn{2}{|l|}{ Types of surgical wounds and the risk of infection } & $\begin{array}{c}\text { Risk of } \\
\text { infection (\%) }\end{array}$ \\
\hline Clean & $\begin{array}{l}\text { Elective procedure, primarily closed wound without trauma and with no evidence of infection } \\
\text { or inflammation in the surgical site. Without compromising the integrity of the gastrointestinal } \\
\text { tract, urogenital tract, respiratory tract, oral cavity and pharynx - providing aseptic technique has } \\
\text { been used }\end{array}$ & $<2$ \\
\hline $\begin{array}{l}\text { Clean-con- } \\
\text { taminated }\end{array}$ & $\begin{array}{l}\text { Procedures in which the urinary, respiratory or gastrointestinal tracts are entered under con- } \\
\text { trolled conditions, without evident contamination with their contents. Procedures involving the } \\
\text { biliary tract with no evidence of infection; procedures involving access through the oropharyngeal } \\
\text { mucosa; clean emergency procedures; repeat surgery within 7 days of a clean procedure. Blunt } \\
\text { trauma }\end{array}$ & 20 \\
\hline $\begin{array}{l}\text { Contami- } \\
\text { nated }\end{array}$ & $\begin{array}{l}\text { Open post-traumatic wound, procedure with a violation of the aseptic technique; inflammation } \\
\text { other than surgical site infection; penetrating trauma within less than } 4 \text { h of the procedure; } \\
\text { chronic wound eligible for treatment with a skin graft }\end{array}$ \\
\hline Dirty & $\begin{array}{l}\text { Penetrating trauma within more than } 4 \mathrm{~h} \text { of the procedure; procedures involving devitalised } \\
\text { tissues; evidence of infection at the surgical site. Preoperative perforation of the gastrointestinal, } \\
\text { biliary or respiratory tracts }\end{array}$ & 40 \\
\hline
\end{tabular}


This classification has also served as the basis for implementing guidelines for the use of perioperative prophylaxis.

Clean wounds in surgery almost always concern elective procedures, which are carried out under sterile conditions. They require prophylaxis only in cases involving the introduction of prosthetic devices or implants and in situations where infection could pose a high risk to the patient (such as operative procedures in the fields of cardiothoracic surgery, neurosurgery, orthopaedic surgery and vascular surgery). Elective inguinal hernia repair procedures are a good example of clean surgical procedures.

The benefits of antibiotic prophylaxis in cleancontaminated and contaminated wounds are indisputable. In cases of dirty wounds, the patient is given antibiotic treatment rather than being provided with antibiotic prophylaxis [27-31].

In clean procedures, such as elective inguinal hernia repair procedures and breast surgery, the use of prophylaxis seems controversial. The SSI rate in clean procedures should not exceed $2 \%$ [32].

It might seem that single doses of antibiotics in perioperative prophylaxis are harmless. However, they always pose a risk of causing an allergic reaction or generating bacterial resistance [33]. As about $30-50 \%$ of antibiotics in hospitals are administered for prophylactic purposes, their unnecessary use is also significant from the economic point of view $[24,34]$.

Guidelines on antibiotic prophylaxis include the indications, the type of antibiotic as well as the timing and method of its administration [25, 35, 36]. The currently applicable guidelines in Poland are those published by the Ministry of Health, authored by Hryniewicz, Kulig et al. and constituting an element of the National Antibiotic Protection Programme.

A single dose of a cephalosporin (e.g. cefazolin) given intravenously, directly before making the incision, is commonly recommended. The prophylaxis is expanded to include subsequent doses if the procedure takes longer than expected [25].

For a certain period of time, there was a trend in the international literature to shift towards oral administration of antibiotic prophylaxis, as a cheaper and simpler alternative to intravenous dosing [37, 38]. Currently in Poland, oral prophylaxis is only recommended for urological procedures.

\section{Risk factors for surgical site infection}

Identification of the risk factors for SSI is of key importance. This follows the assumption that certain patient groups will be able to achieve measurable benefits from using antibiotic prophylaxis in clean operative procedures [39].

As mentioned above, the results of RCTs to assess the use of prophylaxis in hernia repair procedures are inconclusive $[1,5,13-20,40,41]$. Three trials are in favour of using prophylaxis $[5,40,41]$, while nine are against $[1,13-20]$. There is no evidence that unequivocally supports the necessity of using antibiotic prophylaxis for hernia repair procedures.

The EHS guidelines are therefore based on the assumption that prophylaxis in clean operative procedures is unnecessary. Patients with multiple risk factors for SSI are an exception [4, 22]. Classifying patients into groups at low or high SSI risk would allow us to identify those who should be provided with prophylaxis.

The SSI rates are affected by the so-called risk indexes, with the SENIC and NNIS risk indexes being the best known ones [42]. According to the SENIC (Study of the Efficacy of Nosocomial Infection Control) index, the most important risk factors are the following: an abdominal operation; an operation lasting more than $2 \mathrm{~h}$; a surgical site with a wound classification of either contaminated or dirty/infected; an operation performed on a patient having more than 3 discharge diagnoses.

Absence of risk factors predicts the SSI rate at $1 \%$, while the presence of $1,2,3$ and 4 factors is associated with a rate of $3.6 \%, 8.9 \%, 17.2 \%$ and $27.0 \%$, respectively [30, 43].

The NNIS (National Nosocomial Infection Surveillance) system index identifies the following risk factors for SSI:

- A surgical site with a wound classification of either contaminated or dirty/infected.

- An operation lasting more than $2 \mathrm{~h}$ or more than $75 \%$ of the time allocated for the operation.

- The patient's ASA score of more than 3 .

Absence of the above risk factors is associated with an SSI rate of $1.5 \%$, while the presence of 1,2 and 3 factors is associated with a rate of $2.9 \%, 6.8 \%$ and $13.0 \%$, respectively $[25,30,44,45]$. The NNIS system has certain limitations, as it utilises the (often subjective) American Society of Anesthesiologists (ASA) scale [46]. 
An NNIS risk index of 2, in cases of hernia repair procedures, weighs in favour of using prophylaxis, although no evidence to support this could be demonstrated in research studies [47]. However, as the CDC pointed out, risk factors may vary from procedure to procedure [48].

The EHS lists recurrence of hernia, old age $(>70$ years) and immunosuppression as patient-related risk factors for infection. A long duration of the operation and drainage are listed as procedure-related factors. Co-morbidities (diabetes mellitus, rheumatoid arthritis, obesity) are also included among the risk factors [22].

Establishing universal risk factors in the case of hernia repair procedures is not, however, an easy task. Many of these factors are controversial, and their impact on SSI rates is questioned by some [5] Leaving a drain in the postoperative wound may serve as an example. Yerdel et al. [40] reported a significant effect of drainage on an increased rate of SSI, while the results reported by Aufenacker et al. [1] and Tzovaras et al. [16] were quite opposite.

Studies have shown that sex could be a factor significantly affecting the rates of SSI (as demonstrated by the higher rate of SSI in women undergoing hernia repair procedures). Hypoalbuminaemia has also been shown to be an independent risk factor for SSI [1]. It therefore seems necessary to conduct further studies to establish the actual risk factors for SSI [5].

\section{Antibiotic prophylaxis in hernia repair procedures}

Elective hernia repair procedures are considered to be clean procedures which do not, as such, require antibiotic prophylaxis $[6,49,50]$. Antibiotic prophylaxis is not recommended for procedures carried out without a mesh, and this seems to be indisputable. This view is also included in the EHS guidelines [22]. Implantation of a mesh during a hernia repair procedure is, however, theoretically associated with a higher risk of infection [15].

As already mentioned, the benefits of antibiotic prophylaxis in low-risk patients are doubtful. This opinion is shared by the EHS [22] and reflected by most of the published RCTs [1, 13-20].

According to the surveys conducted at hospitals in London and the South East of England, however, more than half of surgeons use antibiotic prophylaxis during hernia repair procedures, including in low- risk patients (i.e. those without risk factors for SSI). They justify their approach by the presence of an implant, despite the lack of sufficient clinical evidence to support this course of action [21].

Furthermore, most surgeons admit that they do not comply with the perioperative antibiotic treatment guidelines followed at their own facility (at hospitals where the guidelines are based on the EHS recommendations) and they administer antibiotic prophylaxis to their patients. They explain this by being "profoundly" convinced that they are doing the right thing [21].

The use of antibiotic prophylaxis is justified by the high rate of clinically significant SSI [25]. The main problem with hernia repair procedures is that it is difficult to establish the actual rate of SSI: depending on the source, the rate varies from $0 \%$ to $14 \%$. Such a considerable divergence may stem from a number of factors. Factors that play a significant role include: the method of post-hospitalisation follow-up (SSI diagnosed by the surgeon vs. an independent observer), the definition of SSI (no definition vs. the CDC definition), duration of post-discharge follow-up (1 week vs. 1 year), study design based on which the rate of SSI is calculated (retrospective non-randomised vs. prospective randomised), etc. [51]. Of particular note is the fact that $50 \%$ of SSI are diagnosed after the patient's discharge, as a result of which the SSI rates may be considerably underestimated [10-12].

Based on the literature, there is a need to include one more factor, often not mentioned directly, which is the "surgical environment". The RCTs and meta-analysis show that medical centres less specialized in hernia repair procedures (general surgery wards vs. hernia repair centres) achieve benefits from using antibiotic prophylaxis. The same correlation seems to take place between economic development of the country, level of health service and incidence of SSI. Those data comply not only with hernia repair procedures, but surgical procedures in general (especially "clean procedures”).

\section{Surgical site infection: costs and consequences}

Surgical procedures on the inguinal canal account for a fourth of all operative interventions in general surgery [52]. Based on the numerous randomised trials and meta-analyses, procedures using 
a mesh have become the gold standard in the surgical repair of inguinal hernia $[2,53,54]$. Procedures using a mesh have reduced the rate of recurrence from $15 \%$ to less than $1 \%[55,56]$.

Recurrent hernia is not, however, the only complication that may develop following procedures carried out using a mesh. The other complications include seromas, haematomas at the surgical site, chronic pain, migration or rejection of the mesh, and SSI.

As with other wounds, SSI complicating surgical repair of an inguinal hernia may be classified into superficial (SSSI) and deep (DSSI). This classification is based on the classification developed in 1992 by the CDC [57-59]. Herniologists often use a simpler classification: infections that do or do not involve a prosthesis.

Most infections arise in the skin and subcutaneous tissue within the first 30 days after surgery (SSSI). Deep infections, involving the fascia and/or muscles, but also the implant itself, may manifest within up to 1 year after surgery and account for the minority of SSI cases [60].

Superficial infections associated with inguinal hernia repair procedures are not as dangerous as those developing in other surgical specialties (neurosurgery, cardiac surgery, orthopaedic surgery). They usually require simple drainage with or without systemic antibiotic treatment [61]. Though troublesome to the patient, they are generally not a major clinical problem.

The DSSI are a serious therapeutic problem and a difficult condition to manage. They usually require prolonged hospitalisation (usually several hospitalisations) and in some cases repeat surgery. The most common causative factors are Staphylococcus aureus and Staphylococcus epidermidis [40, 58, 62]. Mann et al. [59] and Taylor and O'Dwyer [61] reviewed the literature about the fate of infected inguinal hernia grafts, and concluded that this condition frequently necessitates complete removal of grafts [24].

These seemingly easy-to-treat conditions, superficial infections should not, however, be taken lightly.

The development of a complication in the form of an SSI prolongs the patient's hospitalisation by an average of 7 days and increases the hospitalisation costs by about 3000 US dollars (according to the CDC) [24]. These are overall data concerning all surgical procedures (not only those for hernia). In cases of orthopaedic or cardiac surgery, the costs can increase to as much as 30,000 US dollars [24, 63-66].
According to Kirkland et al., patients who develop SSSI are $60 \%$ more likely to require hospitalisation at an ICU, five times more likely to be readmitted to hospital and twice as likely to die during the perioperative period compared to patients without SSSI [63].

As far as hernia repair procedures are concerned, SSSI quadruples the risk of hernia recurrence, although there are sources that do not confirm this $[4,19,67]$. On the other hand, avoidance of using unnecessary prophylaxis not only reduces the costs but also minimises the risk of allergic reactions and of the emergence of bacterial resistance $[22,25]$.

The per-patient cost of prophylaxis estimated by Aufenacker et al. is relatively low (13.54 Euro). Avoidance of using unnecessary prophylaxis could, however, save 10 million Euro in the US and Europe, because $70 \%$ of hernia repair procedures are carried out in patients at a low risk of perioperative infections $[1,68]$.

According to Davey and Nathwani, the additional cost of treating a patient with SSI, in the case of inguinal hernia, is 600 US dollars. The SSI in cases of colorectal surgery increases the per-patient costs by 2,106 US dollars. In spite of all that, the total annual cost of hernia surgery is the same as that of colorectal surgery (44,800 vs. 48,440 US dollars). This is due to the fact that hernia repair procedures are much more common than surgical procedures on the large intestine. This goes to show that the frequency at which a given procedure is performed is equally important as its "quality" [69].

The above cost analysis demonstrates that each improvement in using antibiotic prophylaxis for surgical procedures (including those for hernia) will have a significant impact both in medical and economic terms.

Similar calculations for Polish conditions are lacking, and no reliable cost-effectiveness analysis has been carried out for using antibiotic prophylaxis in patients undergoing hernia repair.

\section{Review of studies}

A large number of research papers and reports on the efficacy of antibiotic prophylaxis in hernia repair procedures have been published in the literature (see Table II). Prospective randomised trials (preferably double-blind ones) are of the greatest value, and 12 such studies have been conducted over the past 
Table II. Randomized controlled trials

\begin{tabular}{|c|c|c|c|c|c|c|c|c|c|}
\hline \multirow[t]{2}{*}{ First author, year } & \multirow[t]{2}{*}{ Country } & \multirow{2}{*}{$\begin{array}{l}\text { Control } \\
\text { group }\end{array}$} & \multirow{2}{*}{$\begin{array}{c}\text { Sample } \\
\text { size }\end{array}$} & \multicolumn{2}{|c|}{ Infections } & \multirow[t]{2}{*}{ Sample size } & \multirow{2}{*}{$\begin{array}{l}\text { Sample } \\
\text { size }\end{array}$} & \multicolumn{2}{|c|}{ Infections } \\
\hline & & & & $n$ & $\%$ & & & $n$ & $\%$ \\
\hline Morales, 2000 & Spain & Placebo & 287 & 6 & 2.09 & Cefazolin 2 g. i.v. & 237 & 4 & 1.7 \\
\hline Yerdel, 2001 & Turkey & Placebo & 133 & 12 & 9.0 & Ampicillin + sulbactam 1.5 g. i.v. & 136 & 1 & 0.7 \\
\hline Aufenacker, 2004 & Netherlands & Placebo & 505 & 9 & 1.8 & Cefazolin 1 g. i.v. & 503 & 8 & 1.6 \\
\hline Celdran, 2004 & Spain & Placebo & 49 & 4 & 8 & Cefazolin 1 g. i.v.. & 50 & 0 & 0 \\
\hline Oteiza, 2004 & Spain & $\begin{array}{l}\text { No treat- } \\
\text { ment }\end{array}$ & 123 & 0 & 0 & $\begin{array}{c}\text { Amoxicillin + clavulanic } \\
\text { acid } 2 \mathrm{~g} \text { i.v. }\end{array}$ & 124 & 1 & \\
\hline Perez, 2005 & Philippines & Placebo & 180 & 7 & 3.9 & Cefazolin 1 g. i.v. & 180 & 4 & 2.2 \\
\hline Tzoravas, 2007 & Greece & Placebo & 193 & 9 & 4.6 & $\begin{array}{c}\text { Amoxicillin + clavulanic } \\
\text { acid } 1.2 \text { g. i.v. }\end{array}$ & 193 & 5 & 2.6 \\
\hline Jain, 2008 & India & Placebo & 60 & 1 & 1.7 & $\begin{array}{c}\text { Amoxicillin + clavulanic } \\
\text { acid } 1.2 \text { g. i.v. }\end{array}$ & 60 & 1 & 1.7 \\
\hline Shankar, 2010 & India & Placebo & 162 & 17 & 10.5 & Cefazolin $1 \mathrm{~g}$.i.v. & 172 & 12 & 7 \\
\hline Ergul, 2011 & Turkey & Placebo & 100 & 7 & 7 & Cefazolin $1 \mathrm{~g}$.i.v. & 100 & 5 & 5 \\
\hline Othman, 2011 & Egypt & Placebo & 48 & 6 & 2.88 & $\begin{array}{c}\text { Amoxicillin + clavulanic } \\
\text { acid } 1.2 \text { g. i.v. }\end{array}$ & 50 & 4 & 2 \\
\hline \multirow[t]{2}{*}{ Mazaki, 2013} & Japan & Placebo & 100 & 13 & 13 & Cefazolin 1 g. i.v. & 100 & 2 & 2 \\
\hline & & & 1940 & 91 & 4.7 & & 1905 & 47 & 2.5 \\
\hline
\end{tabular}

15 years $[1,5,13-20,40,41]$. Three of them demonstrated efficacy of prophylaxis in the prevention of SSI [5, 40, 41], while 9 recommended against its routine use [1, 13-20].

The contradictory results and the fact that most of them have been conducted in a relatively small group of patients makes it impossible to draw an unequivocal conclusion.

In 2001, a large, prospective, randomised, double-blind trial was conducted in Turkey to evaluate the use of antibiotic prophylaxis in hernia repair procedures. The efficacy of intravenous administration of ampicillin plus sulbactam for the prevention of SSI in patients undergoing an elective Lichtenstein procedure was evaluated [40].

In a study population of 269 patients, Yerdel et al. demonstrated that the frequency of perioperative infections in the control (placebo) group was 9\% [40]. The study did not reach sufficient power (334 patients were required) and had to be terminated early due to the large number of infections in the placebo group. The rate of SSI in the antibiotic-treated group reached the value of $0.7 \%$ (1 in 136 patients). Such a considerable difference between the groups and such a high rate of infections in the control group generated discussion in the medical community.
In 2003, a Cochrane meta-analysis showed that antibiotic prophylaxis in inguinal hernia repair procedures could neither be unequivocally recommended nor rejected [70]. It was concluded that the problem remained unsolved. Further studies were postulated.

In response to the above meta-analysis, a prospective, multicentre, double-blind, randomised, placebo-controlled trial was conducted [1]. It was hypothesised that antibiotic prophylaxis would reduce the rate of SSI from $4 \%$ to $1 \%$ in hernia repair procedures. A total of 1008 patients were included in the study (against the initially planned sample size of 978), but no significant difference in the rate of SSI was demonstrated between the patients receiving antibiotic prophylaxis and those receiving placebo (1.6\% vs. $1.8 \%$ ) [1].

It was concluded that prophylaxis in low-risk patients was unjustified and unnecessarily increased the costs of hernia repair procedures using a mesh [1]. Despite the objections and limitations reported by other investigators regarding the study by Aufenacker et al. (such as the lack of stratification into low-risk and high-risk subgroups, exclusion of patients below 35 years of age, and failure to calculate the patients' body mass index (BMI) values), this has been the largest and best-designed RCT so far. 
The study has also generated several interesting conclusions. It was shown that age above 60 years, prolonged duration of the operation, and bilateral hernia are not independent risk factors for SSI in hernia repair procedures.

It was also revealed that females undergoing hernia repair had a higher rate of SSI, although no good explanation of this fact could be found.

The study by Celdran et al. and the one by Perez et al. were both conducted on a small sample of patients and were therefore insufficiently powered. The study by Perez et al. was burdened with a high probability of type II error. The weakness of the test makes it impossible to draw hard conclusions [15].

The study by Celdran et al. was designed to include a larger number of patients but was prematurely terminated due to the high rate of infection in the control group (8\%) [41]. The total number of enrolled patients was 89 . The SSI was observed in 4 out of 49 patients in the control group. The remaining studies listed in Table II found no significant differences in the rate of SSI between the control group and the antibiotic prophylaxis group and, as such, confirmed the conclusions drawn by Aufenacker et al. [13-30].

The most recent study has been conducted in Japan by Mazaki et al. (published in April 2014) [5]. Similarly to the studies by Celdran et al. and by Yerdel et al., this study was designed for a larger sample of subjects (400 patients) but was also prematurely terminated (after accrual of 200 patients) due to the high rate of infection in the placebo group (13\%). It was concluded that the number of SSSI cases dramatically decreased among the patients provided with antibiotic prophylaxis. This conclusion was valid for the patients at a low and at a high risk of perioperative infections [5]. The patients provided with prophylaxis also developed a lower number of other complications than the placebo group (e.g. haematoma, seroma, orchitis, urinary tract infection). The study did not reveal any effect of antibiotic prophylaxis on the rate of DSSI.

The authors explained the high rate of SSI in the placebo group (13\%) by including patients with a higher number of risk factors than the patients participating in the previous RCTs. The study population included patients over the age of 70 years, patients with diabetes mellitus and ASA III patients. Also the duration of surgery exceeding 60 min was not an exclusion criterion.
Eighty-three percent of the procedures in this study were carried out by surgeons in training, and all the SSI cases developed in patients operated on by residents. Although it was previously demonstrated that the surgeon's rank was not a significant risk factor for SSI [4, 11, 47], this is nevertheless an interesting finding.

The authors stressed the necessity of further studies on the subject with a particular emphasis on such aspects as (among other things) the necessity to establish the actual risk factors in patients undergoing hernia repair procedures [5].

\section{Discussion}

The rate of SSI in studies confirming the efficacy of antibiotic prophylaxis in hernia repair procedures is surprisingly high $[5,40,41]$.

These values are at least twice as high compared to those in studies that have demonstrated no effect of antibiotic prophylaxis on SSI rates [1, 13-20].

Although the authors explain this issue by underestimating the number of SSSI and by excluding patients at a high risk of SSI from the study populations in other RCTs, some thought should be given to the conclusions they draw.

Such significant differences raise the suspicion that the surgical technique, haemostasis and postoperative care might contribute to the rate of SSI in hernia repair procedures much more than antibiotic prophylaxis alone. One of the major problems with the RCTs conducted so far is the low number of patients in each of the study groups. A correct evaluation of each of these studies and the demonstration of statistically significant differences between the control group and the group provided with antibiotic prophylaxis require much higher numbers of patients.

As Sanchez-Manuel and Seco-Gil demonstrated in their meta-analysis, detection of a $50 \%$ difference between an antibiotic and placebo in an RCT requires 800 patients in each of the two arms [70]. With low numbers of SSI cases in both groups, the results can be confounded.

Most studies leave the issue of using perioperative prophylaxis unresolved. Use of antibiotic prophylaxis is still a subject of many controversies [71].

Interestingly, an analysis of the summary of studies in Table II and the addition of patients from individual studies reveals a significant difference in the overall rate of SSI (4.7\% vs. $2.5 \%)$. However, 
Aufenacker, in a comment on the survey by Aiken et al. [21], warned against the danger of maintaining such statistics and their impact on the current guidelines. He similarly commented on the meta-analyses conducted so far and their unfounded "elevation" above the good RCTs [72].

\section{Conclusions}

Antibiotic prophylaxis in elective repair surgery for inguinal hernia remains a controversial issue. The 2009 EHS guidelines recommend avoiding the use of prophylaxis in low-risk patients but considering it in patients at a high risk of SSI.

It is very likely that these recommendations will soon be reviewed. The more recent RCTs (e.g. the study by Mazaki et al. conducted in Japan) demonstrate that the problem remains unsolved and a large group of surgeons, based on their own experience, present an opinion that opposes the EHS recommendations.

The participants of the first world hernia conference in Milan in 2015 addressed the need to review the current recommendations on antibiotic prophylaxis in hernia repair procedures. In accordance with the principles of evidence-based medicine (EBM), insufficient evidence to support a given course of action weighs against its implementation (in this case, against implementing antibiotic prophylaxis as routine course of action in elective repair procedures for inguinal hernia).

The EBM requires that due consideration should be given to the results of research studies (RCTs in particular) but also requires that the following question is answered: do the results of research studies directly translate to practice and my patients?

It seems that facilities with high SSI rates (> 4-5\%) should consider implementing antibiotic prophylaxis even in low-risk patients and should benefit measurably from it (reduced SSI rates).

At the same time, the reason(s) for such high rates of SSI at these facilities should also be investigated, particularly taking into account the fact that such procedures as shaving the surgical site one day before the elective procedure and aspiration of seromas continue to be common. The above practices are also routinely used in studies to estimate the rate of SSI.

It should also be kept in mind that the use of unlimited antibiotic prophylaxis as the only prevention of nosocomial infections does not solve the problem.

\section{Conflict of interest}

The authors declare no conflict of interest.

\section{References}

1. Aufenacker TJ, van Geldere D, van Mesdag T, et al. The role of antibiotic prophylaxis in prevention of wound infection ater Lichtenstein open mesh hernia repair o primary inguinal hernia. A multicenter double-blind randomized controlled trial. Ann Surg 2004; 240: 955-61.

2. EU Hernia Trialists Collaboration. Repair of groin hernia with synthetic mesh: meta-analysis of randomized controlled trials. Ann Surg 2002; 235: 322-32.

3. Wang J, Ji G, Yang Z, et al. Prospective randomized, doubleblind, placebo controlled trial to evaluate infection prevention in adult patients after tension-free inguinal hernia repair. Int J Clin Pharm Ther 2013; 51: 924-31.

4. Śmietański M, Chrościcki A, Dąbrowicki S, et al. Groin hernia treatment. European Hernia Society Guidelines and comments by the Polish Working Group for the guidelines implementation. Videosurgery Miniinv 2009; 4 (Suppl 1): 40-52.

5. Mazaki T, Mado, K, Masuda H, et al. A randomized trial of antibiotic prophylaxis for the prevention of surgical site infection after open mesh-plug hernia repair. Am J Surg 2014; 207: 476-84.

6. Platt R, Zalenznik DF, Hopkins CC, et al. Perioperative antibiotic prophylaxis for herniorrhaphy and breast surgery. N Engl I Med 1990; 322: 153-60.

7. Hetzer FH, Hotz T, Steinke W, et al. Gold standard for inguinal hernia repair: Shouldice or Lichtenstein? Hernia 1999; 3: 117-20.

8. Stephenson BM. Complications of open groin hernia repair. Surg Clin North Am 2003; 83: 1255-78.

9. Lazorthes F, Chiotasso P, Massip P, et al. Local antibiotic prophylaxis in inguinal hernia repair. Surg Gynecol Obstet 1992; 175: 569-70.

10. Bailey SI, Karran SE, Toyn K, et al. Community surveillance of complications after hernia surgery. BMJ 1992; 304: 469-71.

11. Taylor EW, Byrne DJ, Leaper DJ, et al. Antibiotic prophylaxis and open groin hernia repair. World J Surg 1997; 21: 811-5.

12. Santos KRN, Neto GPB, Fonseca LS, et al. Incidence surveillance of wound infection in hernia surgery during hospitalization and after discharge in a university hospital. J Hosp Infect 1997; 36: 229-33.

13. Morales R, Carmona A, Pagan A. Utilidad de la profilaxis antibiotica en la reduccion de la infeccion de herida en la reperacion de la hernia inguinal o crural mediane malla de polipropileno. Cir Esp 2000; 67: 51-9.

14. Oteiza F, Ciga MA, Ortiz H. Profilaxis antibiotica en la hernioplastia inguinal. Cir Esp 2004; 75: 69-71.

15. Perez AR, Roxas MF, Hilvano SS. A randomized, double-blind, placebo-controlled trial to determine effectiveness of antibiotic prophylaxis for tension-free mesh herniorrhaphy. J Am Coll Surg 2005; 200: 393-8.

16. Tzoravas G, Delikoukos S, Christodoulides G, et al. The role of antibiotic prophylaxis in elective tension-free mesh inguinal hernia repair: results of a single-centre prospective randomized trial. Int J Clin Pract 2007; 61: 236-9. 
17. Jain SK, Jayant M, Norbu C. The role of antibiotic prophylaxis in mesh repair of primary inguinal hernias using prolene hernia system: a randomized prospective double-blind control trial. Trop Doct 2008; 38: 80-2.

18. Shankar VG, Srinivasan K, Sistla SC, et al. Prophylactic antibiotics in open mesh repair of inguinal hernia - a randomized controlled trial. Int J Surg 2010; 86: 444-7.

19. Ergul Z, Akinci M, Ugurlu C, et al. Prophylactic antibiotic use in elective inguinal hernioplasty in a trauma center. Hernia 2011; 16: 145-51.

20. Othman I. Prospective randomized evaluation of prophylactic antibiotic usage in patients undergoing tension free inguinal hernioplasty. Hernia 2011; 15: 309-13.

21. Aiken AM, Haddow JB, Symons NRA, et al. Use of antibiotic prophylaxis in elective inguinal hernia repair in adults in London and south-east England: a cross-sectional survey. Hernia 2013; 17: 657-64

22. Simons MP, Aufenacker T, Bay-Nielsen M, et al. European Hernia Society guidelines on the treatment of inguinal hernia in adult patients. Hernia 2009; 13: 343-403.

23. Polish Hernia Study Group. Post mesh herniorrhaphy infection Analysis of two series of patients. Zakażenia 2006; 4: 2-7.

24. Terzi C. Antimicrobial prophylaxis in clean surgery with special focus on inguinal hernia repair with mesh. J Hosp Infect 2006 62: 427-36.

25. Hryniewicz W, Kulig J, Ozorowski T, et al. Stosowanie antybiotyków w profilaktyce okołooperacyjnej. Narodowy Instytut Leków, Warsaw 2011; 1-27.

26. Altemeier WA. Postsurgical infections. Antibiot Chemother 1976; 21: $11-31$

27. Burke JF. The effective period of preventive antibiotic action in experimental incision of dermal lesions. Surgery 1961; 50: 161-8.

28. Polk Jr HC, Trachtenberg L, Finn MP. Antibiotic activity in surgical incisions: the basis for prophylaxis in selected operations. JAMA 1980; 224: 1353-4.

29. Di Piro JT, Vallner JJ, Bowden TA, et al. Intraoperative serum and tissue activity of cefazolin and cefoxitin. Arch Surg 1985; 120: 829-32.

30. Montewka M, Skrzek A, Plewik D, et al. Zakażenia miejsca operowanego - charakterystyka czynników ryzyka, endogennych źródeł zakażenia i metody zapobiegania. Post Mikrobiol 2012; 51: 227-35.

31. Olson MM, Lee JJ. Continous, 10-year wound infection surveillance. Results, advantages, and unanswered questions. Arch Surg 1990; 125: 794-803.

32. Fry DE. Basic aspects of and general problems in surgical infections. Surg Infect (Larchmt) 2001; 2 (Suppl 1): 3-11.

33. Waldwogel FA, Vaudaux PE, Pittet D, et al. Perioperative antibiotic prophylaxis of wound and foreign body infections: microbial factors affecting efficacy. Rev Infect Dis 1991; 13 (Suppl): 782-9.

34. Ross F, Jones N, Townend A, et al. The cost of inappropriate an tibiotic prophylaxis in inguinal hernia repair surgery. Int I Surg 2015; 23 (Suppl 1): 72-3.

35. Dellinger EP, Gross PA, Barrett TL, et al. Quality standard for antibiotic prophylaxis in surgical procedures: Infectious Diseases Society of America. Clin Infect Dis 1994; 18: 422-7.
36. Page CP, Bohnen JM, Fletcher JR, et al. Antimicrobial prophylaxis for surgical wounds: guidelines for clinical care. Arch Surg 1993; 128: 78-88.

37. Terzi C, Kilic D, Unek T, et al. Single-dose oral ciprofloxacin compared with single-dose intravenous cefazolin for prophylaxis in inguinal hernia: a controlled randomized clinical study. J Hosp Infect 2005; 60: 340-7.

38. Kuzu MA, Hazinedaroglu S, Dolalan S, et al. Prevention of surgical site infection after open prosthetic inguinal hernia repair: efficacy of parenteral versus oral prophylaxis with amoxicillin-clavulanic acid in randomized clinical trial. World J Surg 2005; 29: 794-9.

39. Pessaux P, Atallah D, Lermite E, et al. Risk factors for prediction of surgical site infections in "clean surgery". Am J Infect Control 2005; 33: 292-8.

40. Yerdel MA, Akin EB, Dolalan S, et al. Effect of single-dose prophylactic ampicillin and sulbactam on wound infection after tension-free inguinal hernia repair with polypropylene mesh. Ann Surg 2001; 233: 26-33.

41. Celdran A, Frieyro O, da Pinta JC, et al. The role of antibiotic prophylaxis on wound infection after mesh repair under local anaesthesia on an ambulatory basis. Hernia 2004; 8: 20-2.

42. Mangram AJ, Horan TC, Pearson ML, et al. Guideline for the prevention of surgical site infection. Infect Control Hosp Epidemiol 2002; 23: 183-9.

43. Ortega G, Rhee DS, Papandria JD, et al. An evaluation of Surgical Site Infections by Wound Classification System using the ACS-NSQIP. J Surgical Res 2012; 174: 33-8.

44. Culver DH, Horan TC, Gaynes RP, et al. Surgical wound infection rates by wound class, operative procedures and patient risk index. Am J Med 1991; 91 (Suppl 3B): 152-7.

45. Gaynes RP, Culver DH, Horan TC, et al. Surgical site infection (SSI) rates in the United States, 1992-1998: the National Nocosomial Infections Surveillance System basic SSI risk index. Clin Infect Dis 2001; 33 (Suppl 2): 69-77.

46. Salad M. Grading of patients for surgical procedures. Anesthesiology 1941; 2: 281-4

47. Taylor EW, Duffy K, Lee K, et al. Surgical site infection after groin hernia repair. Br J Surg 2004; 91: 105-11.

48. Gaynes RP. Surgical-site infections and the NNIS SSI risk index: room for improvement. Infect Control Hosp Epidemiol 2000; 21: 184-5.

49. Lewi RT, Weigand FM, Mamazza J, et al. Should antibiotic prophylaxis be used routinely in clean surgical procedures: a tentative yes. Surgery 1995; 118: 742-6.

50. D’Amico DF, Parimbelli P, Ruffolo C. Antibiotic prophylaxis in clean surgery: breast surgery and hernia repair. J Chemother 2001; 13: 108-11.

51. Wittmann DH, Schein M, Condon RE. Antibiotic prophylaxis in wall hernia surgery: never, always, or selectively? Probl Gen Surg 1995; 12: 47-55.

52. Kingsnorth A, LeBlanc K. Hernias: inguinal and incisional. Lancet 2003; 362: 1561-71. 
53. Wrijland WW, van den Tol MP, Luijendijk RW, et al. Randomized clinical trial of non-mesh versus mesh repair or primary inguinal hernia. Br J Surg 2002; 89: 293-7.

54. Rutkow IM. Demographic and socioeconomic aspects of hernia repair in the United States in 2003. Surg Clin North Am 2003; 83: 1045-51.

55. Kehlet $\mathrm{H}$, Bay-Nielsen $\mathrm{M}$. Nationwide quality improvement of groin gernia repair from the Danish Hernia Database of 87,840 patients from 1998 to 2005. Hernia 2008; 12: 1-7.

56. EU Hernia Trialists Collaboration. Mesh compared with nonmesh methods of open groin hernia repair: systematic review of randomized controlled trials. Br J Surg 2000; 87: 854-9.

57. Cruse PJ, Ford R. The epidemiology of wound infection: a 10year prospective study of 62,939 wounds. Surg Clin North Am 1980; 60: 27-40.

58. Horan TC, Gaynes RP, Martone WJ, et al. CDC definitions of nosocomial surgical site infections 1992: a modification of CDC definitions of surgical wound infections. Infect Control Hosp Epidemiol 1992: 13: 606-8.

59. Mann DV, Prout J, Havranek E, et al. Late-onset deep prosthetic infection following mesh repair of inguinal hernia. Am J Surg 1998; 176: 12-4.

60. Biswas S. Elective inguinal hernia repair with mesh: is there a need for antibiotic prophylaxis? A review. World J Surg 2005; 29: 830-6.

61. Taylor SG, O'Dwyer PJ. Chronic groin sepsis following tension free inguinal hernioplasty. Br J Surg 1999; 86: 562-5.

62. Classen DC, Evans RC, Pestotnik SL. The timing of prophylactic administration of antibiotics and the risk of surgical wound infection. N Engl J Med 1992; 326: 281-6.

63. Kirkland KB, Briggs JP, Trivette SL, et al. The impact of surgical site infections in the 1990s: attributable mortality, excess lenght of hospitalization and extra costs. Infect Control Hosp Epidemiol 1999; 20: 725-30.

64. Hollenbeak CS, Murphy D, Dunagan WC, et al. Nonrandom selection and the attributable cost of surgical-site infections. Infect Control Hosp Epidemiol 2002; 23: 174-6.

65. Jenney AW, Harrington GA, Russo PL, et al. Cost of surgical site infections following coronary artery bypass surgery. Aust NZ J Surg 2001; 71: 662-4.

66. Whitehouse JD, Friedman ND, Kirkland KB, et al. The impact of surgical site infections following orthopedic surgery at a community hospital and university hospital: adverse quality of life, excess length of stay and extra cost. Infect Control Hosp Epidemiol 2002; 23: 183-9.

67. Gilbert Al, Felton LL. Infection in inguinal hernia repair considering biomaterials and antibiotics. Surg Gynecol Obstet 1993; 177: 126-30.

68. Aufenacker TJ, Koelemay MJ, Gouma DJ, et al. Systematic review and meta-analysis of the effectiveness of antibiotic prophylaxis in prevention of wound infection after mesh repair of abdominal wall hernia. Br J Surg 2006; 93: 5-10.

69. Davey PG, Nathwani D. What is value of preventing post-operative infections? New Horiz 1998; 6: 64-71.

70. Sanchez-Manuel FJ, Seco-Gil JL. Antibiotic prophylaxis for hernia repair. (Cochrane Review). The Cochrane Librarary. Issue 1, John Wiley \& Sons Ltd., Chichester, UK 2004.
71. Kamtoh G, Pach R, Kibil W, et al. Effectiveness of mesh hernioplasty in incarcerated inguinal hernias. Videosurgery Miniinv 2014; 9: 415-9.

72. Aufenacker TJ. The danger of performing meta-analysis and the impact of guidelines. Hernia 2013; 17: 665-8.

Received: 7.04.2016, accepted: 26.09.2016. 